\title{
PREMEDICATION PRACTICE FOR NEONATAL INTUBATION IN FRENCH NICUS AND PICUS: DESCRIPTION, ANALYSIS AND IDENTIFICATION OF POTENTIAL BARRIERS TO GOOD PRACTICE IMPLEMENTATION
}

\author{
X. Durrmeyer ${ }^{1,2}$, P. Daoud ${ }^{3}$, P. Boileau ${ }^{4}$, S. Renolleau ${ }^{5}$, P.-H. Jarreau ${ }^{6}$, C. Saizou ${ }^{7}$, A. Lapillonne ${ }^{8}$, M. \\ Granier $^{9}$, P. Durand ${ }^{10}$, R. Lenclen ${ }^{11}$, A. Coursol ${ }^{12}$, P. Hubert ${ }^{13}$, L. de Saint Blanquat ${ }^{13}$, R. Carbajal ${ }^{2,14}$ \\ ${ }^{I} N I C U$, Centre Hospitalier Intercommunal de Créteil, Créteil, ${ }^{2}$ U953, INSERM, Paris, ${ }^{3}$ NICU, CHI Andre \\ Gregoire, Montreuil, ${ }^{4}$ NICU, Hopital Antoine Beclère, Clamart, ${ }^{5}$ PICU, Hopital Trousseau, ${ }^{6}$ NICU, Hopital \\ Cochin-Saint Vincent de Paul, ${ }^{7}$ PICU, Hopital Robert Debré, ${ }^{8}$ NICU, Hopital Necker, Paris, ${ }^{9}$ NICU, Hopital \\ Sud-Francilien, Evry, ${ }^{10}$ PICU, Hopital Bicêtre, Kremlin-Bicêtre, ${ }^{11}$ NICU, CHI Poissy-St Germain en Laye, \\ Poissy, ${ }^{12}$ NICU, CH René Dubos, Pontoise, ${ }^{13}$ PICU, Hopital Necker, ${ }^{14}$ Pediatric Emergency Department, \\ Hopital Trousseau, Paris, France
}

Background and aims: Endotracheal intubation is frequently performed in neonates hospitalized in ICUs. The aim of this study was to describe premedication practices in French centres and to identify factors associated with premedication use.

Methods: The EPIPPAIN study (JAMA 2008) was designed as a prospective observational study to collect bedside data on all painful or stressful procedures performed in neonates admitted to 13 tertiary care centres in the Paris Region. All endotracheal intubations performed during this study were analysed. Patients and centres characteristics were tested for their association with the absence/presence of a specific premedication prior to endotracheal intubation.

Results: Out of 101 performed intubations, specific premedication rate was $55.6 \%$ and included mostly opioids (66\%) and midazolam (52\%). When compared to recent guidance from the American Academy of Pediatrics (Pediatrics 2010), used premedications could be classified as "acceptable" (20\%), "preferred" (10\%), "not recommended" (25\%) or "not described" (45\%). In univariate analysis, factors associated with premedication for intubation were: later day of hospitalization at intubation (3.9 vs $2.3, \mathrm{p}<0.05)$, noninvasive ventilation prior to intubation $(61 \%$ vs $28 \%, \mathrm{p}=0.02)$ and a lower analgesia rate for all other painful procedures $(22 \%$ vs $35 \%, \mathrm{p}=0.03)$. In multivariate analysis, only non-invasive ventilation was associated with premedication for intubation. No centre-associated factors were identified for the use of premedication.

Conclusions: Premedication use prior to endotracheal intubation in neonates is extremely heterogeneous. Non-invasive ventilation is associated with higher use of premedication. Efforts are urgently needed to help caregivers implement evidence-based practice in this area. 